\title{
Assessment of Provincial Financial Agglomeration Level Based on Internet Big Data
}

\author{
Xiaonan Huang ${ }^{1,2}$, Mu Zhang ${ }^{1}$ \\ 1.School of Big Data Application and Economics, Guizhou University of Finance and Economics \\ 2.Guizhou Institution for Technology Innovation \& Entrepreneurship Investment, Guizhou University of Finance and Economics \\ Guiyang, China \\ rim_007@163.com
}

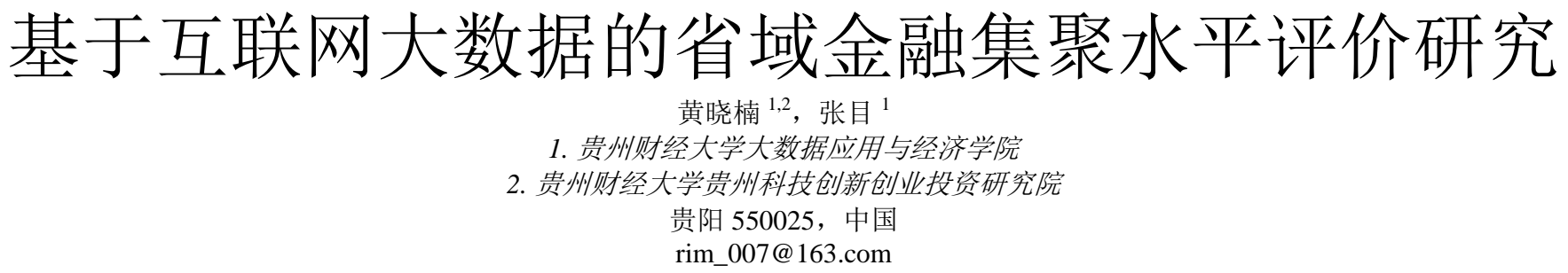

\begin{abstract}
Scientific evaluation of China's financial agglomeration level is of great significance to promote the stable development of China's financial industry and give full play to the role of financial agglomeration in economic promotion. Aiming at the insufficient evaluation index system of financial agglomeration level and the lack of hesitation and fuzziness in evaluation methods, this paper introduces Baidu Search Index to construct an evaluation index system of financial agglomeration level from four aspects: financial industry, banking industry, securities industry and insurance industry. Based on the original data of 31 provinces (cities and districts) in China from 2013 to 2017, this paper evaluates the financial agglomeration level of 31 provinces (cities and districts) in China by using TOPSIS grey relational projection method with hesitation fuzzy language. The empirical results show that, in terms of time, except Tibet, the financial agglomeration level of the remaining 30 provinces (cities and districts) in China shows a trend of fluctuating growth, among which Guangdong, Beijing and Zhejiang rank the top three. Spatially, Beijing and Guangdong rank first and second in the financial agglomeration level, and the financial agglomeration level in the eastern coastal areas is significantly higher than that in the western areas.
\end{abstract}

Keywords-Level of financial agglomeration;Baidu index; Hesitant fuzzy linguistic term set; TOPSIS grey relation projection method

摘要一科学评价我国金融集聚水平，对促进我国金融业稳 定发展, 充分发挥金融集聚对经济助推作用具有重要意义。文 章针对目前金融集聚水平评价指标体系不充分和评价方法缺乏 犹豫性、模糊性的局限, 引入百度搜索指数, 从金融业、银行 业、证券业、保险业四个方面构建金融集聚水平评价指标体系; 并选取 2013-2017 年我国 31 个省（市、区）的原始数据, 采 用犹豫模糊语言 TOPSIS 灰色关联投影法对我国 31 个省（市、 区）的金融集聚水平进行实证评价。实证结果表明：从时间上 看, 除西藏外, 我国其余 30 个省（市、区）的金融集聚水平 都呈现出波动增长的态势, 其中广东、北京、浙江的增幅位列 前三位; 从空间上看, 北京、广东的金融集聚水平位列全国第 一和第二, 且东部沿海地区的金融集聚水平明显高于西部地区。

\section{I. 引言}

金融产业集聚是指一国的金融监管部门、金融中介 机构、跨国金融企业、国内金融企业等具有总部功能的 机构在地域上向特定区域集中，并与其他国际性（跨国） 机构、跨国公司、国内大型企业总部之间存在密切往来 联系的特殊产业空间结构（360 百科）。2017 年 7 月， 习近平总书记在全国金融工作会议上强调 “金融是国家 重要的核心竞争力”。2019 年 3 月, 第十三届全国人民 代表大会第二次会议上，国务院总理李克强在《政府工 作报告》中指出要 “以服务实体经济为导向, 改革优化 金融体系结构”。金融是实体经济的血脉, 我国金融业 发展对经济增长的贡献度稳步提高, 从 2010 年到 2017 年, 我国金融业增加值占 GDP 的比重从 $6.2 \%$ 上升到了 $8.0 \%$ 。由此可见, 加快推动我国金融业集聚发展, 充分 发挥金融集聚效应，对保持经济持续健康发展和社会稳 定起到重要作用。

对金融集聚水平进行评价是当前研究金融发展的重 点。现有文献对金融集聚评价主要分为两个方面, 一个 是指标体系的构建, 另一个是评价方法的选择。1）指标 体系构建。丁艺 (2009) ${ }^{[1]}$ 从金融总体规模、银行业、 证券业和保险业四个方面构见中国金融集聚程度评级指 标体系。茹乐峰等 (2014) ${ }^{[2]}$ 从金融背景、金融规模、 金融密度和金融深度四个方面构建金融水平测度指标体 系。李静（2014） ${ }^{[3]}$ 构建的地区金融集聚水平评价指标 体系包含了保险市场、信贷市场、信托市场和证券市场 张贵平（2018） ${ }^{[4]}$ 建立了包含金融效率、银行业、证券 业和保险业四个方面的上海市金融集聚水平评级指标体 系。卢红光等（2019） ${ }^{[5]}$ 构建的江苏省金融集聚水平评 价体系含有金融环境、金融规模、金融密度、金融深度 等方面；2）评价方法选择。目前文献中评价金融集聚水 平主要采用以下几种方法: 主成分分析法 ${ }^{[1]}$ 、因子分析 法 $^{[2,3]}$ 、赫芬达尔指数法 ${ }^{[6]}$ 、区位熵法 ${ }^{[7]}$ 、熵权 TOPSIS 法 [8]等。现有评价研究为本文指标体系的构建和评价方法 的选取提供了良好的借鉴, 但评价体系忽略了互联网大 数据的利用, 导致信息不充分; 另外, 现有评价方法在 
模糊性、犹豫性问题方面具有局限性, 难以面对模糊不 确定信息做出科学评价。

百度指数是以百度海量网民行为数据为基础的数据 分享平台, 是当前互联网乃至整个数据时代最重要的统 计分析平台之一, 它是以网页搜索和新闻搜索为基础的 免费海量数据分析服务, 用以反映不同关键词在过去一 段时间里的 “用户关注度” 和 “媒体关注度” 。运用百 度指数可以发现、共享和挖掘互联网上最有价值的信息 （360 百科）。目前，百度指数已广泛应用于股票市场表 现 ${ }^{[9]}$ 、投资者情绪 ${ }^{[10]}$ 、旅游舆情 ${ }^{[11]}$ 、房地产价格 ${ }^{[12]}$ 、城 市网络特征 ${ }^{[13]}$ 等领域研究。

多属性决策问题是现实生活中普遍存在的问题, 且 由于决策问题的复杂性和不确定性, 我们很难用确切的 数字去评价, 而是经常给出模糊不定的信息。针对这一 问题, Rodríguez et al (2012) ${ }^{[14]}$ 提出了犹豫模糊语言集 的概念和模型, 通过犹豫模糊语言集, 可以使用多个语 义术语来表达决策偏好, 更好的满足实际决策需求。目 前, 犹豫模糊语言已经广泛应用于川酒品牌评价 ${ }^{[15]}$ 、灾
害风险评估 ${ }^{[16]}$ 、服务商选择 ${ }^{[17]}$ 、军事训练 ${ }^{[18]}$ 、高等教育 发展 ${ }^{[19]}$ 等方面。

由上可知，针对目前金融集聚水平评价指标体系不 充分和评价方法缺乏犹豫性、模糊性的局限，本文将引 入百度指数, 从金融业、银行业、证券业、保险业四个 方面构建金融集聚水平评价指标体系，然后选取 20132017 年我国 31 个省（市、区）的原始数据, 采用犹豫模 糊语言 TOPSIS 灰色关联投影法对我国 31 个省（市、区） 的金融集聚水平进行实证评价，基于评价结果提出相应 的政策建议。

\section{II. 省域金融集聚水平评价指标体系构建}

本文根据金融集聚的内涵，在现有文献对金融集聚 水平衡量指标的研究基础上, 结合金融产业的集聚特征, 遵循代表性、客观性、针对性、可比性的原则, 将百度 搜索指数引入到指标体系中, 从金融业、银行业、证券 业、保险业四个方面构建了包含 4 个一级指标和 20 个二 级指标的金融集聚水平指标体系，如表 1 所示。

表 1. 金融集聚水平测度指标体系

\begin{tabular}{|c|c|c|c|}
\hline 目标层 & 一级指标 & 二级指标 (单位) & 变量 \\
\hline \multirow{20}{*}{ 金融集聚水平 } & \multirow{5}{*}{ 金融业 } & 金融百度搜索指数 & $X_{1}$ \\
\hline & & 金融业增加值(亿元) & $X_{2}$ \\
\hline & & 金融业从业人员 & $X_{3}$ \\
\hline & & 金融业固定资产投资 & $X_{4}$ \\
\hline & & 金融业区位熵 & $X_{5}$ \\
\hline & \multirow{5}{*}{ 银行业 } & 银行百度搜索指数 & $X_{6}$ \\
\hline & & 银行业金融机构存款余额（万元） & $X_{7}$ \\
\hline & & 银行业金融机构贷款余额（万元） & $X_{8}$ \\
\hline & & 居民储蓄存款余额（亿元） & $X_{9}$ \\
\hline & & 银行业区位熵 & $X_{10}$ \\
\hline & \multirow{5}{*}{ 证券业 } & 证券百度搜索指数 & $X_{11}$ \\
\hline & & 境内上市公司数（家） & $X_{12}$ \\
\hline & & 股票市价总值（亿元） & $X_{13}$ \\
\hline & & 上市公司股票筹资额（亿元） & $X_{14}$ \\
\hline & & 证券业区位熵 & $X_{15}$ \\
\hline & \multirow{5}{*}{ 保险业 } & 保险百度搜索指数 & $X_{16}$ \\
\hline & & 保险费收入（亿元） & $X_{17}$ \\
\hline & & 保险密度（元/人) & $X_{18}$ \\
\hline & & 保险深度(\%) & $X_{19}$ \\
\hline & & 保险业区位熵 & $X_{20}$ \\
\hline
\end{tabular}


指标说明：1）区位商, 又称专门化率。其作为衡量 某一区域要素的空间分布情况的指标, 反映了某一产业 部门的专业化程度, 可具体比较各地区产业集聚程度差 异。其计算公式为 $L Q_{i j}=\left(q_{i j} / q_{j}\right) /\left(q_{i} / q\right)$, 其中, $q_{i j}$ 表 示 $j$ 地区 $i$ 产业的总产值, $q_{j}$ 表示 $j$ 地区所有产业的总产值 $q_{i}$ 表示全国 $i$ 产业的总产值, $q$ 表示全国所有产业的总产 值。

2) 百度搜索指数, 是以网民在百度的搜索量为数据 基础, 以关键词为统计对象, 科学分析并计算出各个关 键词在百度网页搜索中搜索频次的加权和。根据搜索来 源的不同, 搜索指数分为 PC 搜索指数和移动搜索指数 (http://index.baidu.com）。

III. 基于犹豫模糊语言的 TOPSIS 灰色关联投影法

\section{A. 基础知识}

定义 $1^{[15]}$ 设 $\mathrm{X}$ 为一给定集合, 根据函数 $\mathrm{h}$ 定义 $\mathrm{X}$ 上 的一个犹豫模糊集，当函数 $\mathrm{h}$ 应用于 $\mathrm{X}$ 时返回 $[0,1]$ 的一 个子集。为了更好的理解, 用如下数学符号来表示犹豫 模糊集:

$$
\mathrm{A}=\left\{<\mathrm{x}, h_{A}(x)>\mid \mathrm{x} \in \mathrm{X}\right\}
$$

其中, $h_{A}(x)$ 是 [0,1]中的一组值, 表示元素 $\mathrm{x} \in \mathrm{X}$ 对集合 $\mathrm{A}$ 的可能隶属度, 并称 $\mathrm{h}=h_{A}(x)$ 为一个犹豫模糊元。

定义 $2^{[15]}$ 设 $E_{G_{H}}$ 为将文本自由语法 $G_{H}$ 生成的语言表 达式 $l l \in S_{l l}$ 转化为犹豫模糊集 $H_{S}$ 的函数, $\mathrm{S}$ 为语法 $G_{H}$ 所 采用的语言术语集, $S_{l l}$ 为语法 $G_{H}$ 所生成的所有表达式的 集合, 则由语法 $G_{H}$ 的生成规则所生成的语言表达式可通 过转化公式 $E_{G_{H}}: S_{l l} \rightarrow H_{S}$ 转换为犹豫模糊语言集:

$$
E_{G_{H}}\left(s_{t}\right)=\left\{s_{t} \mid s_{t} \in S\right\} ;
$$

$E_{G_{H}}\left(\right.$ 至多 $\left.s_{m}\right)=\left\{s_{t} \mid s_{t} \in S\right.$ 且 $\left.s_{t} \leq s_{m}\right\} ;$

$E_{G_{H}}\left(\right.$ 少于 $\left.s_{m}\right)=\left\{s_{t} \mid s_{t} \in S\right.$ 且 $\left.s_{t}<s_{m}\right\} ;$

$E_{G_{H}}\left(\right.$ 至少 $\left.s_{m}\right)=\left\{s_{t} \mid s_{t} \in S\right.$ 且 $\left.s_{t} \geq s_{m}\right\} ;$

$E_{G_{H}}\left(\right.$ 多于 $\left.s_{m}\right)=\left\{s_{t} \mid s_{t} \in S\right.$ 且 $\left.s_{t}>s_{m}\right\}$;

$E_{G_{H}}\left(\right.$ 在 $s_{m}$ 和 $s_{n}$ 之间 $)=\left\{s_{t} \mid s_{t} \in S\right.$ 且 $\left.s_{m} \leq s_{t} \leq s_{n}\right\} 。$

定义 $3^{[20]}$ 设 $s_{\alpha}, s_{\beta}$ 为一个语言术语集的两个元素, 且 $\lambda \in[0,1]$, 则应满足以下特性:

(1) $s_{\alpha} \oplus s_{\beta}=s_{\alpha+\beta}$;

(2) $\lambda s_{\alpha}=s_{\lambda \alpha}$;

(3) $s_{\alpha} \otimes s_{\beta}=s_{\beta} \otimes s_{\alpha}=s_{\alpha \beta}$

在某些情况下, 对于两个不同的犹豫模糊语言数, 其所包含的语言术语的个数可能不同, 为了对两个犹豫 模糊语言数进行正确运算, 在这里本文参照文献[15]中 的思想对具有较少语言术语的犹豫模糊语言数进行增加 语言。设 $b=\left\{b_{l} \mid l=1,2, \cdots, \# b\right\}$ 为犹豫模糊语言数, $\# b$ 为 $b$ 中语言术语的个数, 令 $b^{+}$和 $b^{-}$分别为 $b$ 中最大和最 小的语言术语, $\xi(0 \leqslant \xi \leqslant 1)$ 为一个优化参数, 则在较 少的犹豫模糊语言数中增加的语言术语 $b$ 为 $b=\xi b^{+} \oplus\left(1^{-}\right.$ $\xi) b^{-}$, 本文取 $\xi=0.5$ 。

定义 $4^{[15]}$ 犹豫模糊语言的正理想解 $A^{+}$和负理想解 $A^{-}$ 分别为: $A^{+}=\left\{h_{s}^{1+}, h_{s}^{2+}, \cdots, h_{s}^{n+}\right\}, A^{-}=\left\{h_{s}^{1-}, h_{s}^{2-}, \cdots, h_{s}^{n-}\right\}$, 其中 $(\mathrm{j}=1,2, \ldots, \mathrm{n})$,

$$
\begin{gathered}
h_{s}^{j+}=\left\{\begin{array}{l}
\max _{i=1,2,3, \ldots, m} h_{s}^{i j+}=\max _{\substack{i=1,2,3, \ldots, m \\
l=1, \ldots, h_{s}^{i j}}}\left\{s_{\delta_{l}^{i j}}\right\}, \text { 对收益型属性 } \\
\min _{i=1,2,3, \ldots, m} h_{s}^{i j-}=\min _{\substack{i=1,2,3, \ldots, m \\
l=1, \ldots, \ldots h_{s}^{i j}}}\left\{s_{\delta_{l}^{i j}}^{i j}\right\}, \text { 对成本型属性 }
\end{array}\right. \\
h_{s}^{j-}=\left\{\begin{array}{l}
\max _{i=1,2,3, \ldots, m} h_{s}^{i j+}=\max _{\substack{i=1,2,3, \ldots, m \\
l=1, \ldots, \# h_{s}^{i j}}}\left\{s_{\delta_{l}^{i j}}\right\}, \text { 对成本型属性 } \\
\min _{i=1,2,3, \ldots, m} h_{s}^{i j-}=\min _{\substack{i=1,2,3, \ldots, m \\
l=1, \ldots, \# h_{s}^{i j}}}\left\{s_{\delta_{l}^{i j}}\right\}, \text { 对收益型属性 }
\end{array}\right.
\end{gathered}
$$

定义 $\mathbf{5}^{[20]}$ 设 $\mathrm{S}$ 为语言术语集, $H_{S}^{1}=\left\{b_{1}^{1}, b_{2}^{1}, \ldots, b_{l}^{1}\right\}$ 和 $H_{S}^{2}=\left\{b_{1}^{2}, b_{2}^{2}, \ldots, b_{l}^{2}\right\}$ 是 $\mathrm{S}$ 上的两犹豫模糊语言术语集, 记 $\delta(\bullet)$ 为虚拟语言术语下标, 令

$$
d\left(H_{S}^{1}, H_{S}^{2}\right)=\left(\frac{1}{l} \sum_{i=1}^{l}\left(\frac{\delta\left(b_{i}^{1}\right)-\delta\left(b_{i}^{2}\right)}{2 q}\right)^{2}\right)^{1 / 2}
$$

则称 $d\left(H_{S}^{1}, H_{S}^{2}\right)$ 为 $H_{S}^{1}$ 和 $H_{S}^{2}$ 间的标准欧式距离。

\section{B. 犹豫模糊语言TOPSIS 灰色关联投影法计算步骤}

步骤 1: 根据决策需要定义一个多属性决策问题: 确定由 $\mathrm{m}$ 个方案组成的方案集 $\mathrm{A}=\left\{A_{1}, A_{2}, \ldots, A_{m}\right\}$, 由 $\mathrm{n}$ 个属性组成的属性集 $\mathrm{X}=\left\{X_{1}, X_{2}, \ldots, X_{n}\right\}$ 。对上述决策问题 用语言表达式对各个属性 $X_{j}$ 下的每一个方案 $A_{i}$ 的表现给 出定性评估。利用文本自由语法 $G_{H}$ 生成语言表达式 $l l$, 根据定义 2 给出的转化函数将文本自由语法 $G_{H}$ 生成的语 言表达式 $l l \in S_{l l}$ 转化为犹豫模糊集 $H_{S}$ 的函数。同时, 为 了对两个犹豫模糊语言数进行正确运算, 添加新的语言 术语, 使得每个犹豫模糊语言数包含相同的语言术语个 数。

步骤 2: 正、负理想决策矩阵的确定。已知被评价 对象为 $i=(1,2, \ldots, m)$, 评价指标为 $j=(1,2, \ldots, n)$ 。 $h_{i j}$ 表示第 $i$ 个被评价对象在第 $j$ 个评价指标下的评价值, 构建原始 决策矩阵为:

$$
H=\left\{h_{i j}\right\}_{m \times n}=\left(\begin{array}{ccc}
h_{11} & \cdots & h_{1 n} \\
\vdots & \ddots & \vdots \\
h_{m 1} & \cdots & h_{m n}
\end{array}\right)
$$

取第 $j$ 个评价指标下各个被评价对象的最大值作为正 理想方案, 最小值为负理想方案, 得到以下两个基准方 案:

正理想方案为: $A^{+}=\left\{h_{01}^{+}, h_{02}^{+}, \ldots, h_{0 n}^{+}\right\}, h_{0 j}^{+}=$ $\max _{i}\left(h_{i j}\right)$

负理想方案为: $A^{-}=\left\{h_{01}^{-}, h_{02}^{-}, \ldots, h_{0 n}^{-}\right\}, h_{0 j}^{-}=$ $\min _{i}\left(h_{i j}\right)$

注: 以上均为正向指标的处理方式, 对于逆向指标 的处理方式本文不再详细说明。

步骤 3: 正、负理想灰色关联系数矩阵的确定。设 方案的理想序列 $X^{*}=\left\{h_{01}^{*}, h_{02}^{*}, \ldots, h_{0 n}^{*}\right\}$, 这里为正理 想方案序列 $A^{+}$与负理想方案序列 $A^{-}$, 则第 $i$ 个被评价对 象在第 $j$ 个评价指标下的关联系数为:

$$
\begin{aligned}
& r_{i j}=\frac{\min _{i} \min _{j}\left|h_{0 j}^{*}-h_{i j}\right|+\rho \max _{i} \max _{j}\left|h_{0 j}^{*}-h_{i j}\right|}{\left|h_{0 j}^{*}-h_{i j}\right|+\rho \max _{i} \max _{j}\left|h_{0 j}^{*}-h_{i j}\right|} \\
& \text { 式中 }\left|h_{0 j}^{*}-h_{i j}\right| \text { 为根据定义 } 5 \text { 计算出的两个犹豫模糊 }
\end{aligned}
$$


语言术语集的标准欧式距离, $\rho$ 是分辨系数, $\rho \in[0,1]$, 一般取 $\rho=0.5$, 得到正、负灰色关联系数矩阵, 其中正理 想灰色关联系数矩阵为:

$$
E^{+}=\left\{r_{i j}^{+}\right\}_{(m+1) \times n}=\left(\begin{array}{ccc}
r_{01}^{+} & \cdots & r_{0 n}^{+} \\
r_{11}^{+} & \cdots & r_{1 n}^{+} \\
\vdots & \ddots & \vdots \\
r_{m 1}^{+} & \cdots & r_{m n}^{+}
\end{array}\right)
$$

负理想灰色关联系数矩阵为:

$$
E^{-}=\left\{r_{i j}^{-}\right\}_{(m+1) \times n}=\left(\begin{array}{ccc}
r_{01}^{-} & \cdots & r_{0 n}^{-} \\
r_{11}^{-} & \cdots & r_{1 n}^{-} \\
\vdots & \ddots & \vdots \\
r_{m 1}^{-} & \cdots & r_{m n}^{-}
\end{array}\right)
$$

步骤 4: 熵权法求取加权灰色关联系数矩阵。在组 合评价问题中，指标权重表示的是指标间的相对重要性 程度, 为了求取加权决策矩阵, 本文采用摘权法对各个 评价指标进客观赋权重。熵权法确定属性权重大致可以 分为以下两步:

（1）对 $\mathrm{m}$ 个方案 $\mathrm{n}$ 个属性的多属性决策矩阵 $\left(h_{i j}\right)_{n \times m}$, 计算第 $j$ 项指标的熵值:

$$
\begin{gathered}
e_{j}=-\frac{1}{\ln n} \sum_{i=1}^{n}(\varepsilon \ln \varepsilon) \\
\sum_{i=1}^{n} h_{i j} \neq 0, j=1,2, \ldots, m
\end{gathered}
$$

其中, $\varepsilon=h_{i j}\left(\sum_{i=1}^{n} h_{i j}\right)^{-1}$, 当 $\varepsilon=0$ 时, $\ln \varepsilon=0$ 。

（2）根据计算熵值的结果，计算各项属性的权重:

$$
w_{j}=1-e_{j} / \sum_{i=1}^{n}\left(1-e_{j}\right), j=1,2, \ldots, m
$$

于是指标权重序列为 $W=\left(w_{1}, \ldots, w_{n}\right)$, 进而计算得 到正、负加权灰色关联系数矩阵, 其中正理想加权灰色 关联系数矩阵为:

$$
F^{+}=\left(\begin{array}{ccc}
w_{1} & \cdots & w_{n} \\
r_{11}^{+} w_{1} & \cdots & r_{1 n}^{+} w_{n} \\
\vdots & \ddots & \vdots \\
r_{m 1}^{+} w_{1} & \cdots & r_{m n}^{+} w_{n}
\end{array}\right)
$$

负理想加权灰色关联系数矩阵为:

$$
F^{-}=\left(\begin{array}{ccc}
w_{1} & \cdots & w_{n} \\
r_{11}^{-} w_{1} & \cdots & r_{1 n}^{-} w_{n} \\
\vdots & \ddots & \vdots \\
r_{m 1}^{-} w_{1} & \cdots & r_{m n}^{-} w_{n}
\end{array}\right)
$$

步骤 5: 确定灰色关联投影贴近度。将每一个方案 看成一个行向量, 则称待评价方案 $A_{i}$ 与理想方案 $A^{*}$ 之间 的夹角为灰色关联投影角, 其余弦值 $\varepsilon_{i}$ 为:

$$
\varepsilon_{i}=\frac{A_{i} * A^{*}}{\left\|A_{i}\right\| \cdot\left\|A^{*}\right\|}=\frac{\sum_{j=1}^{n} w_{j} r_{i j} \cdot w_{j}}{\sqrt{\sum_{j=1}^{n}\left[w_{j} r_{i j}\right]^{2}} \cdot \sqrt{\sum_{j=1}^{n} w_{j}^{2}}}
$$

容易得知, 灰色关联投影角 $\varepsilon_{i}$ 越小, 投影关联度越 大, 待评价方案 $A_{i}$ 越接近于理想方案, 计算待评价方案 $A_{i}$ 在理想方案上的投影值为:

$$
D_{i}=\left\|A_{i}\right\| \cdot \varepsilon_{i}=\frac{A_{i} \cdot A^{*}}{\left\|A^{*}\right\|}=\sum_{j=1}^{n} r_{i j} \frac{w_{j}^{2}}{\sqrt{\sum_{j=1}^{n} w_{j}^{2}}}
$$

称权重序列 $\bar{W}=\left(\overline{w_{1}}, \ldots, \overline{w_{n}}\right)$ 为灰色投影权重矢量, 其中: $\overline{w_{j}}=\frac{w_{j}^{2}}{\sqrt{\sum_{j=1}^{n} w_{j}^{2}}}$ 。

则正理想灰色关联投影值为:

$$
D_{i}^{+}=\sum_{j=1}^{n} r_{i j}^{+} \overline{w_{j}}
$$

负理想灰色关联投影值为:

$$
D_{i}^{-}=\sum_{j=1}^{n} r_{i j}^{-} \overline{w_{j}}
$$

进一步计算得到灰色关联投影贴近度为:

$$
y_{i}=\frac{D_{i}^{+2}}{D_{i}^{+2}+D_{i}^{-2}}
$$

可证明得出结论: $y_{i}$ 越大, 可行方案距离正理想方 案越近; $y_{i}$ 越小, 可行方案距离正理想方案越远 ${ }^{[21]}$ 。

\section{IV. 我国金融集聚水平实证分析}

\section{A. 数据来源}

本文我国 31 省（市、区）的金融百度搜索指数、银 行百度搜索指数、证券百度搜索指数、保险百度搜索指 数数据来源于百度指数网站（http://index.baidu.com）, 其余指标原始数据来自《2013-2017 年中国国民经济和社 会发展统计公报》、《2014-2018 年中国统计年鉴》、

《2013-2017 年各省（市、区）金融运行报告》、国家统 计局网站、RESSET 金融研究数据库。

\section{B. 实证结果与分析}

（1）定义多属性决策问题。由表 1 可知, 确定的方 案集为: $\mathrm{A}=\{$ 北京市, 天津市, 河北省, $\cdots$, 新疆维吾 尔族自治区 $\}$, 属性集 $\mathrm{X}=\left\{X_{1}, X_{2}, X_{3}, \ldots, X_{20}\right\}$ 。同时, 上 述 20 个属性的语言术语集 $\mathrm{S}$ 可以表示为 $\mathrm{S}=\left\{S_{0}=\right.$ 极差, $S_{1}=$ 差, $S_{2}$ =略差, $S_{3}=$ 中等, $S_{4}=$ 略好, $S_{5}=$ 好, $S_{6}=$ 极好 $\} 。$ 根据决策专家对我国 31 个省市的金融集聚的主观评价, 得出我国 31 个省市在 20 个属性下的定性评估数据。运 用转换函数 $E_{G_{H}}$ 将决策专家给出的语言表达式 $l l$ 转换为犹 豫模糊语言数, 并构造犹豫模糊语言评估矩阵 $H_{S}$ (以下 计算过程以 2013 年数据为例）。为准确运算, 需添加新 的语言术语, 使得每个犹豫模糊语言数包含相同个数的 语言术语, 因犹豫模糊语言数包含的语言术语较多, 这 里就不再列出。

（2）本文采用熵权法来计算属性权重，因考虑到数 据的可比性, 故本文计算 2013-2017 年每年的属性权重, 将五年的属性权重加总平均得出一个属性权重平均值, 作为计算每年我国 31 个省市金融集聚水平的属性权重。 所以组成的属 性权重 集为 $\mathrm{W}=\{0.025,0.055,0.037,0.062,0.055,0.030,0.057,0.046,0.042$, $0.024,0.022,0.091,0.129,0.086,0.067,0.030,0.046,0.049,0.024$ $, 0.022\}$ 。

（3）根据上文犹豫模糊语言 TOPSIS 灰色关联投影 法的计算步骤, 计算 2013-2017 年我国 31 个省（市、区） 金融集聚水平对应的灰色关联投影贴近度，具体数值见 表2。 
从表 2 我们可以看到, 排名前五位的依次为北京、 广东、浙江、江苏和上海, 说明这些地区与理想方案最 为接近, 金融集聚水平较高, 属于金融业高集聚区, 而 甘肃、海南、西藏、青海和宁夏属于金融业低集聚区。 除此之外，排名第一的北京市的灰色关联投影贴近度为 0.6113 , 而排名最后的宁夏的灰色关联投影贴近度为 0.1110 , 二者的差值约 0.5 , 金融集聚水平区域差异化比 较明显, 另外前六位的均位于我国东部沿海地区, 而排 名后几位的均位于我国较为贫困的西部地区，区域金融 业发展存在着严重的不均衡。从表 2 观看每个省（市、 区）的时序发展，我们可以看到整体上我国 31 省（市、 区）的金融集聚水平灰色关联投影贴近度都随时间的推 移而逐年增加, 代表从 2013 年至 2017 年期间, 我国金 融集聚程度在总体上呈现出增长的趋势, 各省金融行业 的发展也越来越好。其中，广东 2013 年灰色关联投影贴 近度为 $0.4199,2017$ 年灰色关联投影贴近度为 0.7215 , 灰色关联投影贴近度五年净增 0.3016 ，其金融集聚水平
增幅位居全国第一，其次为北京灰色关联投影贴近度五 年净增 0.2498 ; 但是通过计算西藏的灰色关联投影贴近 度五年净增-0.0096, 且只有该地区金融集聚水平增幅为 负，表示西藏 2013-2017 年金融业发展处在下降的趋势。

对比中国 31 省（市、区）金融集聚水平的空间差异， 从表 2 可以看出, 2013 年中国整体金融集聚程度明显处 于低水平状态，东部沿海地区的金融集聚水平显著高于 内陆地区; 2017 年中国金融集聚水平在空间上存在较大 差异, 金融集聚水平较高的地方主要集中在北京、广东 以及长三角一带, 金融集聚水平较低的地方则是分布在 西北以及西南地区。同时, 对比 2013 年和 2017 年我国 省域金融集聚水平的发展变化, 我们可以发现最近几年 中部和东部地区的金融发展体现出强劲的动力, 像中部 地区的陕西、河南、湖北、湖南等明显看出金融集聚得 到快速发展，金融集聚水平显著提高，东部沿海地区的 金融集聚发展也处在全国前列。从图 1 中我们还可以看

表 2. 我国 31 个省（市、区）金融集聚水平灰色关联投影贴近度

\begin{tabular}{|c|c|c|c|c|c|c|c|}
\hline & 2013 & 2014 & 2015 & 2016 & 2017 & 平均值 & 排名 \\
\hline 北京 & 0.4545 & 0.5231 & 0.7056 & 0.6692 & 0.7043 & 0.6113 & 1 \\
\hline 广东 & 0.4199 & 0.4390 & 0.7010 & 0.6888 & 0.7215 & 0.5941 & 2 \\
\hline 浙江 & 0.2593 & 0.2882 & 0.3979 & 0.4743 & 0.4848 & 0.3809 & 3 \\
\hline 江苏 & 0.2541 & 0.3094 & 0.3979 & 0.4706 & 0.4555 & 0.3775 & 4 \\
\hline 上海 & 0.2406 & 0.2627 & 0.3551 & 0.3778 & 0.4142 & 0.3301 & 5 \\
\hline 山东 & 0.1734 & 0.1982 & 0.2811 & 0.2705 & 0.3074 & 0.2461 & 6 \\
\hline 四川 & 0.1573 & 0.1766 & 0.2097 & 0.2274 & 0.2223 & 0.1987 & 7 \\
\hline 福建 & 0.1518 & 0.1610 & 0.2056 & 0.2062 & 0.1925 & 0.1834 & 8 \\
\hline 安徽 & 0.1478 & 0.1635 & 0.1889 & 0.1800 & 0.2022 & 0.1764 & 9 \\
\hline 湖北 & 0.1469 & 0.1619 & 0.1779 & 0.1760 & 0.2084 & 0.1742 & 10 \\
\hline 河南 & 0.1491 & 0.1568 & 0.1692 & 0.1744 & 0.1835 & 0.1666 & 11 \\
\hline 辽宁 & 0.1661 & 0.1556 & 0.1792 & 0.1532 & 0.1698 & 0.1648 & 12 \\
\hline 湖南 & 0.1395 & 0.1561 & 0.1750 & 0.1663 & 0.1858 & 0.1646 & 13 \\
\hline 河北 & 0.1440 & 0.1449 & 0.1646 & 0.1731 & 0.1772 & 0.1607 & 14 \\
\hline 陕西 & 0.1297 & 0.1428 & 0.1472 & 0.1511 & 0.1557 & 0.1453 & 15 \\
\hline 内蒙古 & 0.1213 & 0.1649 & 0.1438 & 0.1275 & 0.1319 & 0.1379 & 16 \\
\hline 山西 & 0.1274 & 0.1321 & 0.1399 & 0.1471 & 0.1416 & 0.1376 & 17 \\
\hline 天津 & 0.1332 & 0.1446 & 0.1380 & 0.1336 & 0.1369 & 0.1373 & 18 \\
\hline 黑龙江 & 0.1219 & 0.1339 & 0.1325 & 0.1481 & 0.1432 & 0.1359 & 19 \\
\hline 吉林 & 0.1196 & 0.1363 & 0.1287 & 0.1500 & 0.1420 & 0.1353 & 20 \\
\hline 重庆 & 0.1215 & 0.1335 & 0.1333 & 0.1431 & 0.1342 & 0.1331 & 21 \\
\hline 江西 & 0.1215 & 0.1274 & 0.1308 & 0.1415 & 0.1412 & 0.1325 & 22 \\
\hline 新疆 & 0.1172 & 0.1192 & 0.1365 & 0.1354 & 0.1534 & 0.1324 & 23 \\
\hline 广西 & 0.1211 & 0.1266 & 0.1257 & 0.1318 & 0.1347 & 0.1280 & 24 \\
\hline 贵州 & 0.1138 & 0.1180 & 0.1208 & 0.1262 & 0.1531 & 0.1264 & 25 \\
\hline 云南 & 0.1269 & 0.1241 & 0.1240 & 0.1276 & 0.1292 & 0.1263 & 26 \\
\hline 甘肃 & 0.1134 & 0.1220 & 0.1301 & 0.1245 & 0.1239 & 0.1228 & 27 \\
\hline 海南 & 0.1156 & 0.1172 & 0.1225 & 0.1337 & 0.1192 & 0.1216 & 28 \\
\hline 西藏 & 0.1225 & 0.1185 & 0.1254 & 0.1170 & 0.1129 & 0.1193 & 29 \\
\hline 青海 & 0.1102 & 0.1104 & 0.1125 & 0.1142 & 0.1123 & 0.1119 & 30 \\
\hline 宁夏 & 0.1082 & 0.1090 & 0.1119 & 0.1139 & 0.1122 & 0.1110 & 31 \\
\hline
\end{tabular}


到甘肃、宁夏、云南、广西等地的金融集聚发展在 20132017 年期间较为缓慢, 这些省市的经济发展在全国范围 内也处在落后的水平, 金融业发展条件及基础较差, 从 而影响到这些地方的金融集聚发展。

\section{V. 结论与政策建议}

\section{A. 结论}

本文创新性的将百度指数引入到金融集聚水平评价指 标体系中，克服了目前指标体系中信息不充分的缺点; 同时采用犹豫模糊语言 TOPSIS 灰色关联投影法对我国 31 省（市、区）的金融集聚水平进行定量研究，通过计 算灰色关联投影贴近度来反映金融集聚水平。根据实证 结果我们可以得出如下结论:

(1) 从时间上来看, 除西藏外, 我国 31 省（市、区） 的金融集聚水平基本都呈现出波动增长的态势, 体现出 我国 2013 年至 2017 年金融业发展整体上逐渐提高。但 各地区的金融集聚发展速度存在差异, 青海、宁夏等地 的灰色关联投影贴近度增幅在 0.1 左右, 远不及北京、广 东等地区。

（2）从空间上来看，金融集聚水平排名前四位的是 北京、广东、浙江和江苏, 均分布在我国东部沿海地区, 排名后四位的是海南、西藏、青海和宁夏, 反映出我国 金融集聚水平空间差异明显，西部地区的金融业发展有 待提高。

\section{B. 政策建议}

结合以上得出的结论，本文提出以下两点政策建议:

（1）东部地区依靠良好的经济发展基础，政策优势, 拥有丰富的金融资源，而西部地区经济发展实力较弱, 再加上气候、地形、交通等劣势因素，使得西部地区的 金融业发展比较落后，本文的实证结果也证明了我国东 西部金融集聚水平的差异。为了消除这种区域金融发展 不平衡现象，就要根据各个地区金融发展的不同特点， 差异化发展各地区金融业，加大区域间交流与合作，提 高区域间金融要素的流动。特别是宁夏、青海等金融发 展落后的地区，要切实提高金融资源的配置效率，加大 金融基础设施建设, 引进金融人才, 努力降低与其他地 区的金融发展差距。

（2）各个省（市、区）也应当认识到自己在金融发 展中存在的阻碍因素，因地制宜的制定相关发展政策。 西部地区金融集聚发展落后的最关键的因素是其证券业 发展非常落后, 所以西部地区首要做的是发展本地的证 券业, 鼓励当地有实力的企业进行上市, 有意识地实行 适度倾斜的证券产业政策; 而中部地区普遍是银行业发 展不及东部地区，需要加大银行业金融机构的引进力度, 同时营造良好的银行业发展环境, 提高各级银行机构的
竞争力; 像北京、江苏、浙江、广东等金融业发达东部 地区，应该保持现有的稳定发展态势，在各金融行业中 研发创新性产品, 充分利用区位优势展开国际合作, 逐 步迈向高质量发展行列。

\section{致谢}

本项目受国家自然科学基金项目（71861003）和 2017 年度第二批贵州省基础研究计划 (软科学类别) 项目

（黔科合基础（2017）1516-1）联合资助。

$$
\text { 参考文献 }
$$

[1] 丁艺, 李树丞, 李林. 中国金融集聚程度评价分析 [J]. 软科 学, 2009,23(06):9-13.

[2] 茹乐峰,苗长虹,王海江.我国中心城市金融集聚水平与空间格局研 究[J].经济地理,2014,34(02):58-66.

[3] 李静, 白江. 我国地区金融集聚水平的测度 [J]. 求是学 刊, 2014,41(04):52-58

[4] 张贵平.上海市金融集聚水平的测度 [J].时代金融,2018(12):56-57.

[5] 卢红光,蒋涛.金融集聚对区域创新的影响一一基于江苏省 13 个地 级市的空间计量分析 [J].经济研究导刊,2019(16):39-45.

[6] 姜冉.泛珠三角地区金融集聚与经济增长一基于 1982-2007 年的数 据分析[J].经济研究导刊,2010(20):60-61

[7] 廖霄梅, 李顺利. 广西金融集聚水平的测度 [J]. 统计与决 策, 2019,35(10):171-173.

[8] 冯林,刘华军,宋建林.基于熵权 TOPSIS 法的县域金融集聚评价研 究一以山东省为例 [J].山东财经大学学报,2016,28(02):1-9.

[9] 陈植元,米雁翔,厉洋军,郑君君. 基于百度指数的投资者关注度与股 票市场表现的实证分析[J].统计与决策,2016(23):155-157.

[10] 孟雪井,孟祥兰,胡杨洋. 基于文本挖掘和百度指数的投资者情绪指 数研究[J].宏观经济研究,2016(01):144-153.

[11] 刘嘉毅,陈玲,陶婷芳.旅游舆情网络关注度城市差异一一来自 289 个城市百度指数的实证研究 [J].信息资源管理学报, 2018,8(03):93101

[12] 姜文杰,赖一飞,王恺.基于百度指数的房地产价格相关性研究 [J].统 计与决策,2016(02):90-93

[13] 熊丽芳,甄峰,王波,席广亮. 基于百度指数的长三角核心区城市网络 特征研究[J].经济地理,2013,33(07):67-73。

[14] Rodríguez R M, Martínez L, Herrera F. Hesitant fuzzylinguistic terms sets for decision making [J]. IEEE Transactions on Fuzzy Systems, 2012,20:109-119.

[15] 廖虎昌,杨竹,徐泽水,顾新. 犹豫模糊语言 PROMETHEE 方法在川酒 品牌 评价中应用 [J/OL]. 控制与决策 $: 1-$ 10.https://doi.org/10.13195/j.kzyjc.2018.0335.

[16] 徐绪堪,王京.基于犹豫模糊集的城市型水灾害风险评估 [J].统计与 决策,2019,35(05):51-55.

[17] 刘俊.基于犹豫模糊群决策模型的云计算服务商选择 [J].计算机工 程与应用,2018,54(23): 109-114+119.

[18] 李超群,赵华,徐泽水.基于正交投影法的犹豫模糊决策方法及其在 军事训练中应用 $[J]$.模糊系统与数学, 2018,32(02):75-82.

[19] 胡冠中,周志刚.区间犹豫模糊熵应用于地方高等教育发展研究 [J]. 计算机工程与应用,2014,50(23):26-30+86.

[20] 魏翠萍,葛淑娜. 犹豫模糊语言幂均算子及其在群决策中的应用 $[\mathrm{J}]$. 系统科学与数学, $2016,36(08): 1308-1317$.

[21] 柯宏发,陈永光,夏斌.一种基于逼近于理想灰关联投影的多目标决 策算法[J].电子学报,2007(09):1757-1761 